\title{
Efficiency analysis of implementing hybrid printing technologies
}

\author{
Liviu Berculescu ${ }^{1, *}$, Emilia Bălan ${ }^{2}$, Cristina Mohora $^{2}$, and Mariana Tudor ${ }^{1}$ \\ 1 University Politehnica of Bucharest, Doctoral School Engineering and Management of \\ Technological Systems, 313 Splaiul Independenței, 6 sector, 060042, Bucharest, Romania \\ ${ }^{2}$ University Politehnica of Bucharest, Faculty of Engineering and Management of Technological \\ Systems, Machines and Production Systems Department, 313 Splaiul Independenţei, 6 sector, \\ 060042, Bucharest, Romania
}

\begin{abstract}
The paper analyses 4 printing technological flow cases, considering the author's experience (over 15 years) in the printing industry to improve the production efficiency. The productivity, the quality and the delivery time are the main areas of interest for people working in the printing \& finishing industry, where the print demand structure evolved and the costs of replacing machines are very high. The implementation of the organisational and reconfiguration of machines changes contribute to the development of new efficient working structures within the printing process, therefore increasing the efficiency of it, as one can notice from the diagrams presented in the paper. The time and the costs presented have been obtained through a couple of trials of modifying the work parameters, the colour and the materials according to the colour management guidelines in use. Ultimately the optimal technological structure has been chosen for quality improvement, cost and delivery time reduction.
\end{abstract}

\section{Introduction}

In recent years, the polygraphic industry has gone through a fierce competition to adapt to the challenges of easy internet access and aggressive expansion of television, which has significantly reduced the demand for newspapers and glossy magazines, textbooks and books or advertising on printed media (posters, flyers, brochures, catalogues) [1].

On the other hand, the fast evolution of digital printing technologies (laserjet, inkjet) compels classical (offset, flexo, rotogravure) technology users to rethink their production flows, the use of human resources and the design of prints, to be able to withstand the competitive market.

The current trend to diversify the demand for printing products implicitly implies, on the part of manufacturers, a different approach to production processes [2]. Quality, efficiency and delivery time as short as possible are the keywords when it comes to a

\footnotetext{
* Corresponding author: liviu.berculescu@yahoo.com
} 
printed product. The modular architecture of most printing machines allows them to be supplemented, if necessary, with equipment that makes them more versatile and more efficient in operation. The rapid development of digital printing solutions and their integration into the manufacturing streams of offset, flexographic, screen printing, rotogravure or finishing machines has led to the emergence of hybrid manufacturing technologies. They offer the possibility of obtaining complex, high quality products with a short manufacturing time and a highly-improved resource consumption [4].

The concept of streamlining technology flows is the focus of those working in the printing industry, the main reasons being the evolution of print demand structure and the high cost of replacing used machines [3]. This paper analyses methods through which new materials and technologies can be used with up-to-date, efficient equipment, in order to obtain products with high technical qualities (Figure 1).

One of the novelty elements of the work is the analysis of the impact on the efficiency in the polygraphic production of the implementation of hybrid printing technologies adapted to the modular construction equipment. To this end, the analysis made to assess the effects of measures to streamline manufacturing flows in the printing industry can provide relevant information without affecting the company's current production or generating costs by modifying production lines. Efficiency analysis have been applied to four of the most common technological flow structures in native companies in packaging and commercial printing. The optimization proposals are original, being among the first results obtained in the first author's doctoral thesis. Based on the analysis of this information, company management will be able to intervene with appropriate measures in areas where material or human resources are used inefficiently to maintain competitiveness and profitability without recourse to new investment costs.

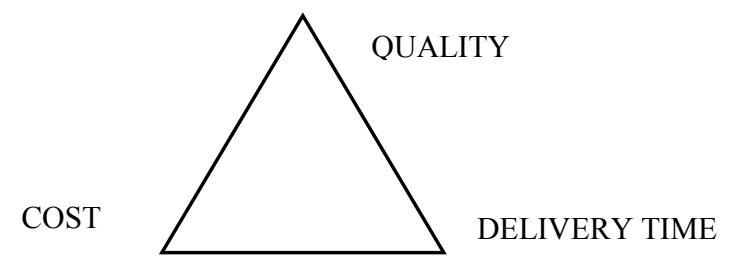

Fig. 1. Triangle of quality.

\section{Hybrid printing systems that combine conventional technologies}

\subsection{Case study no. 1 - Offset printing and spot varnishing}

In the manufacturing of cardboard packaging, selective varnishing is among the most common procedures for improving the aesthetic aspect of the printing. The printing is done on sheet-fed offset printing machines at a speed of $8,000-10,000$ sheets/hour and the selective varnishing operation on flat screen-printing machines is performed at an average work speed of 3,000 sheets/hour, costs manufacturing preparation for screen printing to over 100 euro/ printing job (variant no. 1).

An adaptation of the IR varnishing unit of a sheet-fed offset press (Figure 2) consisting of adding a lamp for the UV varnish drying and replacing the varnishing rubber blanket with a flexo varnishing plate allows the spot varnishing of the printed sheets on the offset printing press at the same pass with the polychrome printing and at the usual printing speed (variant no. 2). 

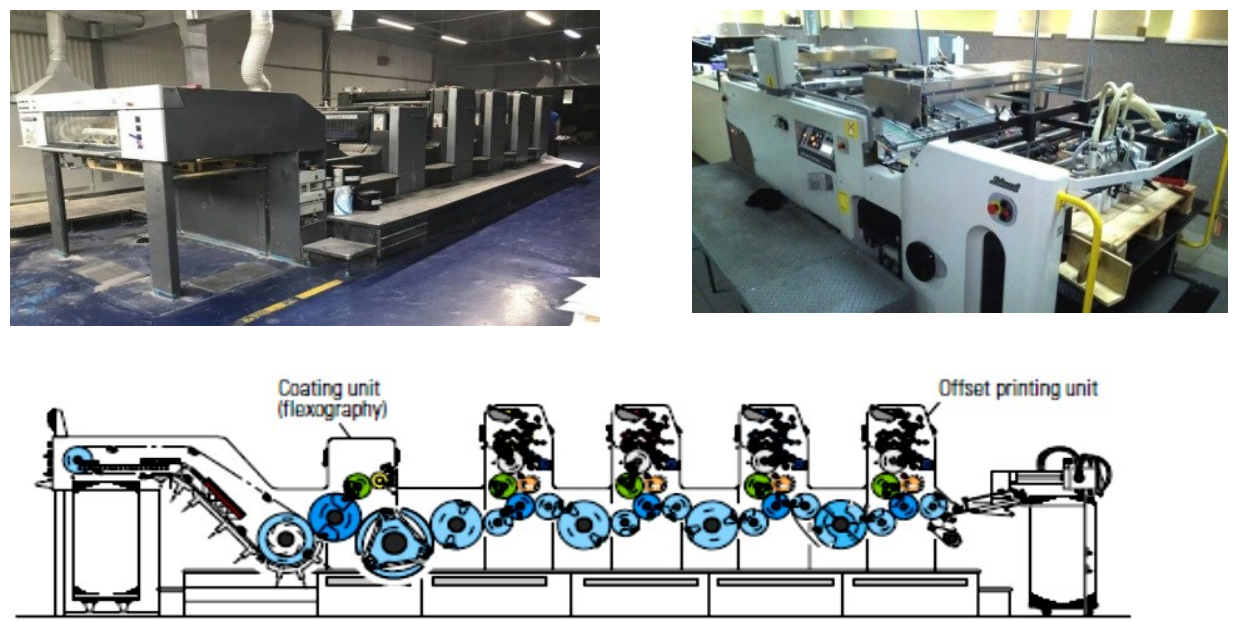

Fig. 2. Adaptation for spot varnishing [1].

After studying the two technological process variants, it was found that after mounting and commissioning of the UV drying lamp and mounting a flexo plate on the varnishing cylinder, the sheets can be spot varnished in line with offset printing. This adaptation makes a screen-printing machine, for room, operator or specific consumable supplies unnecessary, eliminates intermediate storage of printed sheets and piling the once again the sheets into the feeder of the screen printing machine. Following the printing of a print run of 8,000 sheets of cardboard packaging with the flexo UV varnishing made offline on a spot varnishing machine (variant no. 1) and with inline printing and varnishing on the offset press with a flexo varnishing plate in the varnishing unit (variant no. 2), the results are highlighted in the graph in figure 3.

Variant no. 1 - Classic (Figure 3)

- Working time: 90 min print, 180 min varnishing offline;

- Technological waiting time between operations: $480 \mathrm{~min}$. Total time: $750 \mathrm{~min}$;

- Two machines and 4 operators are involved. Labor cost: 54 euro;

- Place for paper storage between operations is required;

- Each of the operations adds technological losses. Technological losses 3.5\%. (280 paperboard sheets).

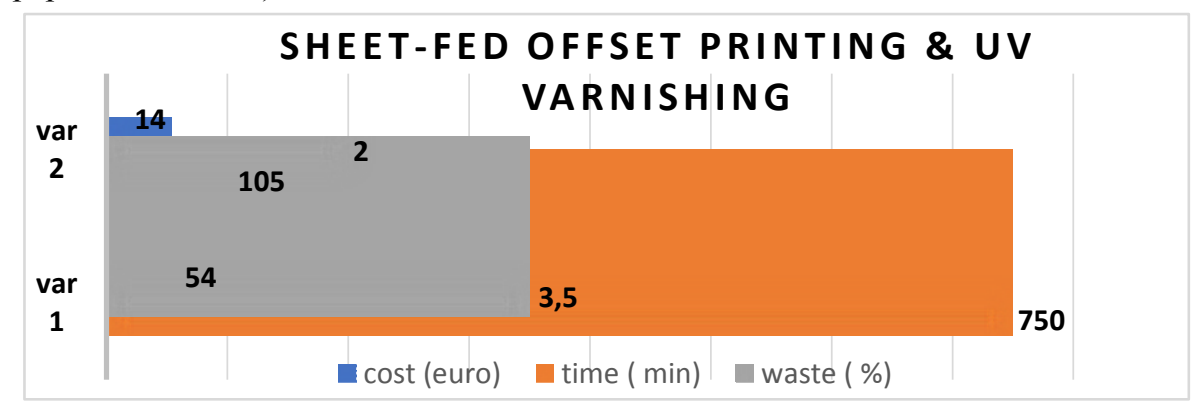

Fig. 3. Difference between classic and optimized variant for spot varnishing.

\section{Variant no. 2 - Optimized (Figure 3)}

- $\quad$ Total working time: $105 \mathrm{~min}$;

- Only the printing machine and 2 operators are needed. Labor cost: 14 euro; 
- No place for paper storage between operations is required;

- The standard technological losses are common to flexo printing and flexo $2 \%$ (160 paperboard sheets).

\subsection{Case study no. 2 - Offset printing and hot stamping vs. Offset printing and cold foil application}

Hot stamping or cold stamping is a method of engraving prints that give the printed sheets highly appreciated aesthetics. Usually, metallic or colored foil is applied thermally, hot stamping (Figure 4), when pressing the printed paperboard together with the hot stamping foil in a die cutting and hot stamping machine. The process consumes a lot of energy, changing jobs involving a long waiting time for cooling or heating the stamp. On the presses designed to print packaging, a special foil applicator may be adapted to transfer the metallized layer to the paperboard by cold stamping as shown in Figure 5. The process takes place at ambient temperature.
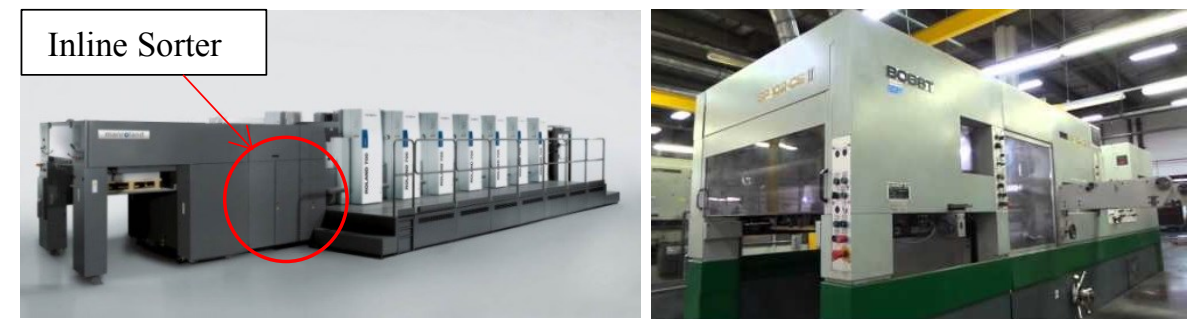

Fig. 4. Offset printing and hot stamping [7].
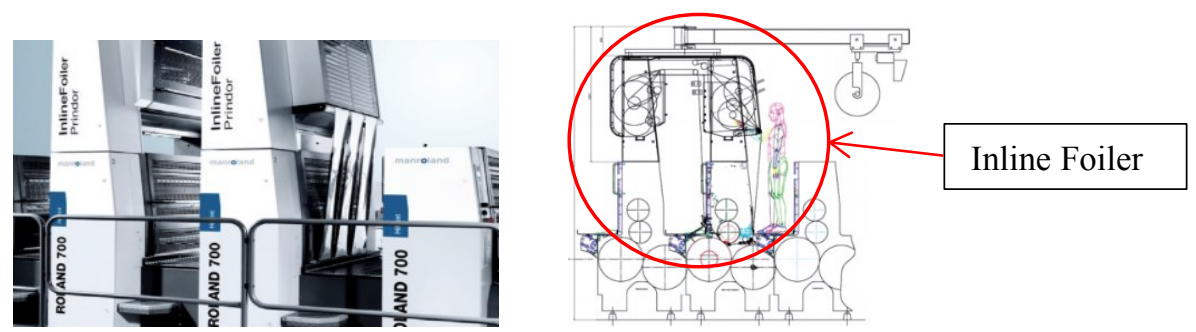

Fig. 5. Offset printing and adaptation for cold foil application with InlineFoiler Prindor system [7].

The InlineFoiler Prindor system is fit to printing units no. 2 and no. 3 (Figure 5). In the first printing unit, an adhesive primer is printed on the carton. The metallized sheet is pressed together with the cardboard sheets into the second printing unit of the printing press between the offset cylinder and impression cylinder and the metallized layer on the foil adheres to the paperboard. The film waste, from which the metallization layer has been transferred to the paper sheets, will rewind in the station placed above of the third printing unit. 5 to 7 rolls of various foils can be used on the press width. It is necessary for the printing machine to have at least six printing units in order to print four colours (CMYK). Aesthetic effects are enhanced by printing over metallized areas using inks suitable for nonabsorbing substrates.

Thus, the sheets destined to become paperboard boxes for packaging can be delivered, already full colour printed, with metallic effect foil and sorted in the machine's inline sorting module. Energy consumption saved from hot stamping is $40 \mathrm{~kW}$ per hour.

Process variants were compared in the case of the printing a 10,000 sheets job of 270 $\mathrm{g} / \mathrm{m}^{2}$ paperboard for candy boxes. 


\section{Variant no. 1 - Classic (Figure 6)}

- Working time: 90 min print + 180 min setup \& hot stamping;

- Technological waiting time between operations: $420 \mathrm{~min}$. Total time: $690 \mathrm{~min}$;

- Two machines and 4 operators are involved. Labor cost: 54 euro;

- Place for paper storage between operations is required;

- Each of the operations adds technological losses (paperboard sheets): $4 \%$.

Variant no. 2 - Optimized (Figure 6)

- Total working time: $110 \mathrm{~min}$;

- $\quad$ Only the printing machine and 2 operators are needed. Labor cost: 8 euros;

- No place for printed paper pallets storage between operations is required;

- Standard technological losses are common for printing and cold foil stamping: $1.7 \%$ (170 paperboard sheet).

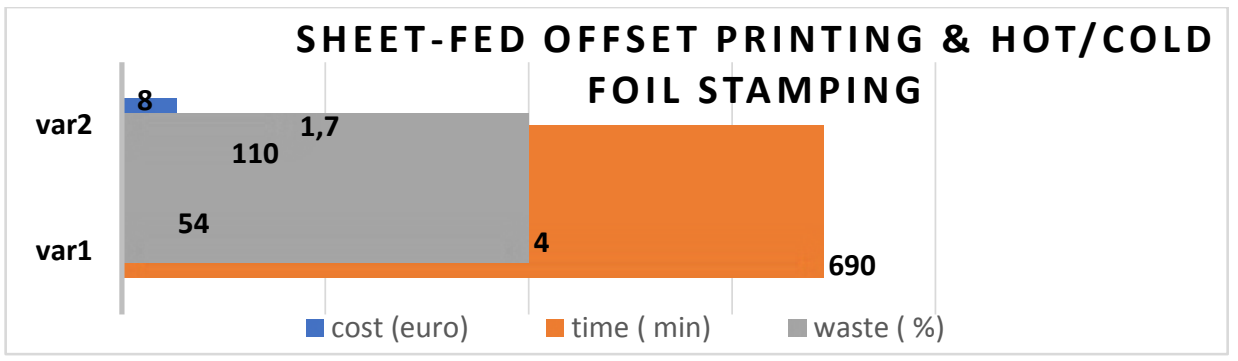

Fig. 6. The difference between the classic variant and the optimized one for the cold foil stamping.

\subsection{Case study no.3 - Labels and flexible packaging - web offset printing}

In the case of offset printing machines for flexible packaging and labels, the web feeders provide superior configuration flexibility. The same advantageous modular construction allows the inclusion of several facilities (Figure 7).

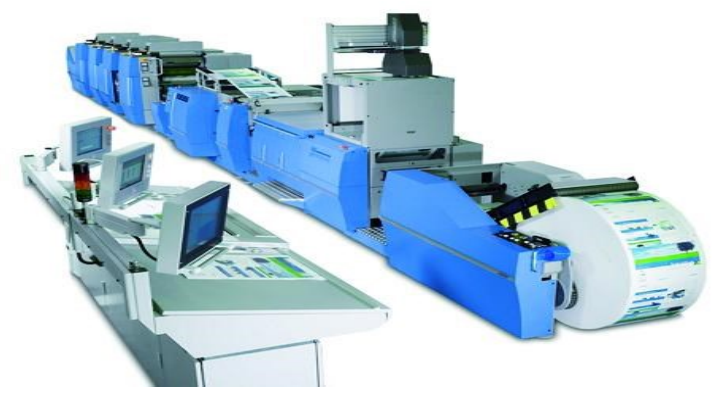

Fig. 7. MullerMartini Alprinta VSOP web offset printing press [8].

Preparing the machine to print a run of 500,000 full color printed and varnished self adhesive paper stickers implied the installation of a flexo printing unit in the fifth unit. The modular construction of the machine, the ability to use Variable Sleeve technology to change the length of the print pattern and the ability to easily convert a printing unit from offset to flexo printing allow a wide range of adaptation to jobs with different features. An example would be to install on the chassis of the last unit a die cutting unit with a flexible die attached to the cylinder.

The printing press can process a wide variety of substrates from self-adhesive paper, lightweight cartons, oriented polypropylene, polyethylene, polyester, etc. 
The printing press modules can be turned on or off depending on the print job. The rotation direction of the rewinding shaft for the printed material can be changed so that the printed material can be rewound face down when needed.

The degree of integration of hybrid technologies in this printing press is high:

- $\quad$ wet offset printing units;

- $\quad$ flexo printing unit;

- $\quad$ rotogravure printing unit;

- $\quad \mathrm{UV}$ or Electron Beam drying systems (EB) when printing food packaging;

- $\quad$ kiss-cut die cutting unit;

- waste rewinding shaft and liner with die cut labels rewinding shaft;

- computerized process control.

Variant no. 1 - classic (Figure 8) Flexo printing + varnishing and offline die cutting

- Printing time: $45 \mathrm{~min}$ settings $+660 \mathrm{~min}$ print $=705 \mathrm{~min}$;

- $\quad$ Stamping time: 15 min settings $+840 \mathrm{~min}$ print $=855 \mathrm{~min}$;

- Two machines and two operators are involved. Labor cost: 111 euro;

- Storage place for printed web between operations is required;

- Each of the operations adds technological losses. Technological losses: $1 \%(\mathrm{~kg})$.

Variant no. 2 - optimized (Figure 8) Web offset printing + inline flexo varnishing + inline kiss-cut die cutting.

- Total working time: 45 min settings +330 min print $=375 \mathrm{~min}$;

- $\quad$ Only the printing machine and 2 operators are needed. Labor cost: 50 euro;

- No storage place for printed substrate is required between operations;

- Standard technological losses are common to printing, varnishing and die cutting: $0.6 \%$.

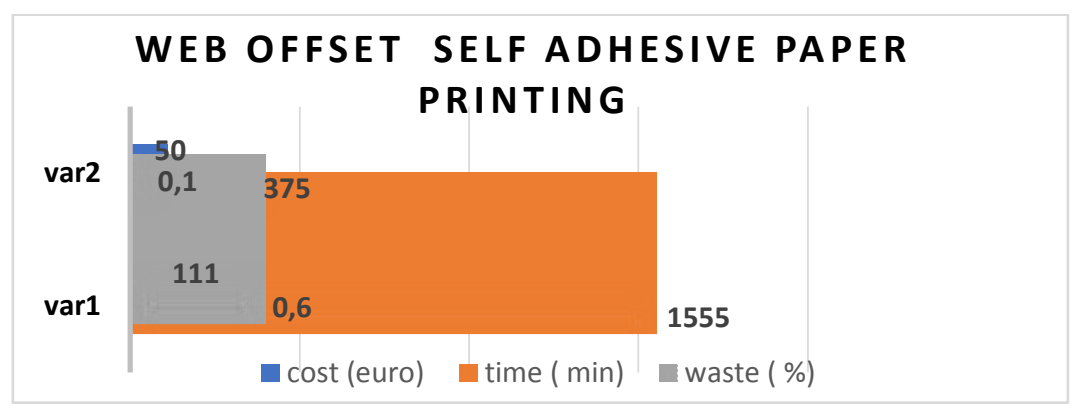

Fig. 8. Difference between classic and optimized variant for web offset printing.

\section{Hybrid printing systems combining conventional technologies with digital technologies (NIP)}

\subsection{Thermal lamination and spot UV varnishing on automatic serigraphic screen-printing machines versus Thermal lamination and digital UV spot varnishing}

Most matt laminated prints are subjected to a procedure for improving the aesthetic aspect of printing by spot varnishing [4]. Typically operations are executed on two different machines: a laminator and a screen printing machine. Operations can be integrated by attaching a cooling conveyor, separating and delivering of the laminated sheets to a paper position detection module and an inline Digital Inkjet UV Spot varnishing printer. It is a 
hybrid machine that combines a standard laminator with a modern nonimpact printing technology, thus reducing both print processing time and technological failures. Worth mentioning that there is no need for a serigraphic screen and the quality of the overlap of the varnish with the pattern is superior. In addition to the transparent glossy varnish other types of varnish, as glitter, can also be used to give special aesthetic effects.

The comparative study for alternative variants was conducted for two technological processes:

Variant no. 1 (Figure 9) was the laminating of the printed sheets on the Autobond 36 SD standard machine and UV spot varnishing on the Sakurai MS-80 UV automatic screenprinting machine for a 4,000-sheet job:

- preparation time for the laminating job: $30 \mathrm{~min}$;

- $\quad$ working speed: 4,000 sheets/hour, laminating time: $60 \mathrm{~min}$;

- preparation time for spot varnishing: $60 \mathrm{~min}$;

- UV varnishing speed: 3,000 sheets/hour, time: $75 \mathrm{~min}$;

- $\quad$ Silk screen cost: 30 euro;

- $\quad$ BOPP matt film for laminating - cost/sheet: 0.04 euro/sheet $=160$ euro;

- $\quad$ varnishing - cost/sheet: 0.055 euro $=220$ euro;

Required time: $225 \mathrm{~min}$. Total costs: 410 euro. Paper loss sheets: 2\% - 80 sheets.
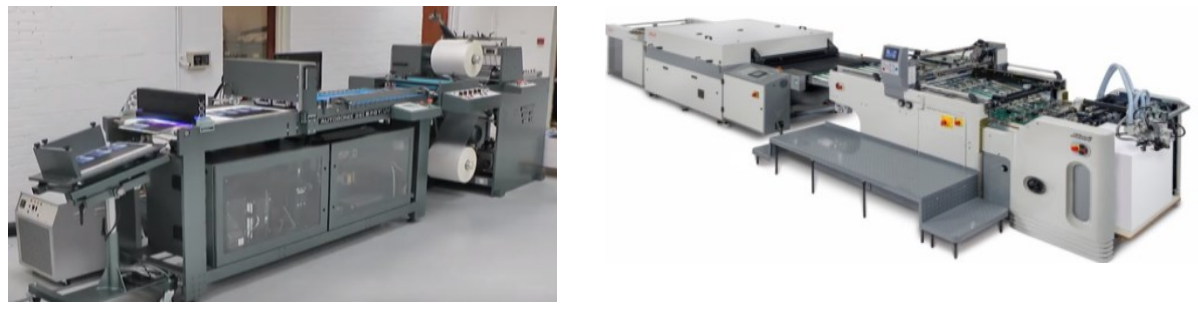

Fig. 9. Autobond 36 SD TP inline digital inkjet Spot UV [8], Sakurai MS-80 UV [10].

Variant no. 2 (Figure 10) was the laminating of the printed sheets and inline digital inkjet UV Spot varnishing on the Autobond 36 SD TP, same job:

- Preparation time for laminating and inline varnishing: $30 \mathrm{~min}$;

- Working speed: 3,200 sheets / hour, total time: $75 \mathrm{~min}$;

- $\quad$ sheet lamination - cost/sheet: 0.04 euro/sheet $=160$ euro;

- $\quad$ spot varnishing - cost/sheet: 0.055 euro/sheet $=220$ euro;

Required time: $105 \mathrm{~min}$. Total costs: 380 euro. Technological losses: $0.1 \%$ - 4 sheets.

\section{MATT LAMINATING \& UV SELECTIVE VARNISHING}

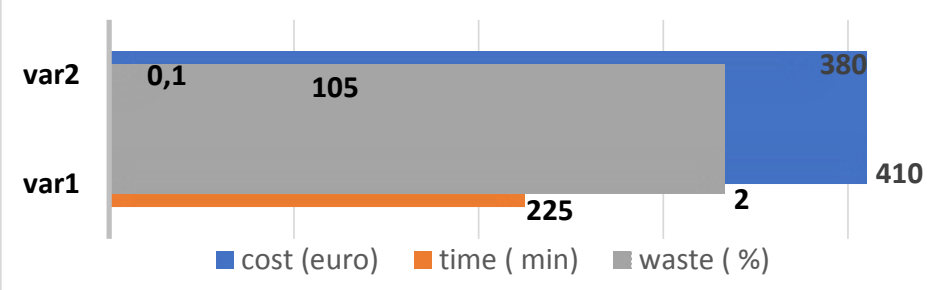

Fig. 10. Difference between matte laminating with offline spot varnishing and matte laminating and inline digital inkjet varnishing. 


\section{Conclusions}

Following the optimization of the polygraphic flows studied during the scientific research within the $\mathrm{PhD}$ thesis of the paper's first author, useful results were obtained, through which the optimization of the classical variants was made as follows:

Case study no. 1: $\mathrm{C}_{\mathrm{C}}=3.86 \times \mathrm{C}_{0} ; \mathrm{T}_{\mathrm{C}}=7.14 \times \mathrm{T}_{0} ; \mathrm{W}_{\mathrm{C}}=1.75 \times \mathrm{W}_{0}$;

Case study no. 2: $\mathrm{C}_{\mathrm{C}}=6.75 \times \mathrm{C}_{0} ; \mathrm{T}_{\mathrm{C}}=6.27 \times \mathrm{T}_{0} ; \mathrm{W}_{\mathrm{C}}=2.35 \times \mathrm{W}_{0}$;

Case study no. 3: $\mathrm{C}_{\mathrm{C}}=2.22 \times \mathrm{C}_{0} ; \mathrm{T}_{\mathrm{C}}=4.15 \times \mathrm{T}_{0} ; \mathrm{W}_{\mathrm{C}}=6 \times \mathrm{W}_{0}$;

Case study no. 4: $\mathrm{C}_{\mathrm{C}}=1.08 \times \mathrm{C}_{0} ; \mathrm{T}_{\mathrm{C}}=2.14 \times \mathrm{T}_{0} ; \mathrm{W}_{\mathrm{C}}=20 \times \mathrm{W}_{0}$;

where the index "c" corresponds to the "classic variant" and the index "o" corresponds to "optimized variant".

The time and the costs presented have been obtained through a couple of trials of modifying the work parameters, the colour and the materials used. Ultimately the optimal variant has been chosen for quality improvement, cost and delivery time reduction.

It also proves that the digitalization of production flows brings many benefits, although at the moment it is very expensive, reason for which many polygraphic companies adopt the hybridization variant. All this demonstrates that the production flows in printing houses are and will always be at the heart of scientific research, their proper efficiency generating a shorter delivery time, outstanding technical features and a low cost of the final product.

\section{References}

1. E. Bălan, L. Berculescu, C. Mohora, C. Dogariu, Annals of the Academy of Romanian Scientists Series on Engineering Sciences, 10, 7 (2018)

2. Yi Xie, Chen-Fu Chien B., Comput. Ind. Eng., 65, 194 (2013)

3. E. Bălan, D. Popa, F.D. Anania, C. Mohora, Innovation and education excellence through vision 2020, I-XI, 5965 (2018)

4. H. Kipphan, Handbook of print media (Springer Verlag Berlin Heidelberg, 2014)

5. S. Petrilă, Ph.D. Thesis, Bacău, 34 (2016)

6. F. J. Lloréns, L. M. Molina, A.J. Verdú, Int. J. Prod. Econ., 98, 3, 273 (2005)

7. http://www.manroland.com/

8. http://staging.qgroupltd.com/muller/wpcontent/uploads/2015/02/Alprinta_V_Web_Offset_Press. $\mathrm{pdf}$

9. https://www.youtube.com/watch? $\mathrm{v}=\mathrm{hnSP}$ 0fleDU

10. https://www.printingnews.com/trade-services/trade-printing/product/12248202/sakurai-usasakurai-ms80all-cylinder-screen-press 